\title{
Influence of Partial Sleep Deprivation on Energy Balance and Insulin Sensitivity in Healthy Women
}

\author{
Anja Bosy-Westphal ${ }^{a}$ Silvia Hinrichs ${ }^{a} \quad$ Kamila Jauch-Chara ${ }^{b}$ Britta Hitze $^{a}$ Wiebke Later $^{a}$ \\ Britta Wilms $^{\mathrm{a}, \mathrm{b}}$ Uta Settler ${ }^{\mathrm{a}} \quad$ Achim Peters $^{\mathrm{b}} \quad$ Dieter Kiosz $^{\mathrm{a}} \quad$ Manfred James Müller $^{\mathrm{a}}$ \\ a Institut für Humanernährung und Lebensmittelkunde, Christian-Albrechts-University Kiel, \\ ${ }^{b}$ Department of Internal Medicine I, University of Lübeck, Germany
}

\section{Key Words}

Sleep deprivation - Energy intake - Energy expenditure . Endocrine regulation of energy balance

\section{Summary}

Background: Voluntary sleep restriction is a lifestyle feature of modern societies that may contribute to obesity and diabetes. The aim of the study was to investigate the impact of partial sleep deprivation on the regulation of energy balance and insulin sensitivity. Subjects and Methods: In a controlled intervention, 14 healthy women (age 23-38 years, BMI 20.0-36.6 kg/ $\mathrm{m}^{2}$ ) were investigated after 2 nights of $>8 \mathrm{~h}$ sleep/night (TO), after 4 nights of consecutively increasing sleep curtailment $(7 \mathrm{~h}$ sleep/ night, 6 h sleep/night, 6 h sleep/night and 4 h sleep/night; T1) and after 2 nights of sleep recovery ( $>8$ h sleep/night; T2). Resting and total energy expenditure (REE, TEE), glucose-induced thermogenesis (GIT), physical activity, energy intake, glucose tolerance and endocrine parameters were assessed. Results: After a decrease in sleep duration, energy intake $(+20 \%)$, body weight $(+0.4 \mathrm{~kg})$, leptin / fat mass $(+29 \%)$, free triiodothyronine $(+19 \%)$, free thyroxine (+10\%) and GIT (+34\%) significantly increased (all $\mathrm{p}<0.05$ ). Mean REE, physical activity, TEE, oral glucose tolerance, and ghrelin levels remained unchanged at T1. The effect of sleep loss on GIT, fT3 and fT4 levels was inversely related to fat mass. Conclusion: Short-term sleep deprivation increased energy intake and led to a net weight gain in women. The effect of sleep restriction on energy expenditure needs to be specifically addressed in future studies using reference methods for total energy expenditure.

\section{Introduction}

Sleep deprivation is an overall lack of the necessary amount of sleep, causing symptoms that interfere with memory, mental abilities, and emotional mood. Besides these well known adverse effects, recent studies suggest a link between the increasing prevalence of overweight/obesity or insulin resistance / type 2 diabetes on the one hand and the trend towards a decreasing sleep duration on the other hand [1-7]. Advancing occupational and social demands contributed to the continuous decline in sleep duration from an average of $9.0 \mathrm{~h}$ a night in 1910 to $7.5 \mathrm{~h}$ by 1975 , and only $6.9 \mathrm{~h}$ today $[8,9]$. Currently, a quarter of the total adult population is increasingly sleepdeprived. In cross-sectional studies an association between a short habitual sleep duration and a higher prevalence of overweight and obesity or a lower body fat mass was found in children and adults [for review see 10]. In addition, very short as well as excessively long habitual sleep durations were both associated with an increased prevalence of impaired glucose tolerance or diabetes [7].

Since cross-sectional data do not rule out reverse causation, chronic sleep loss and impaired quality of sleep may also be a consequence of overweight and obesity. Despite the well documented inverse association between sleep duration and body weight, the influence of partial sleep deprivation on regulation of energy balance has been rarely addressed. Spiegel et al. [11] observed $18 \%$ lower plasma levels of leptin and $24 \%$ higher ghrelin levels in young men following 2 consecutive nights of $4 \mathrm{~h}$ sleep duration when compared to post sleep recovery for 2 nights. Consistent with these findings, the subjects experienced higher rates of hunger and appetite and a favor for energy-dense foods. Since BMI and gender may influence appetite and feeding behavior $[12,13]$, it remains unclear if the results obtained in lean men can be translated to women and a population with a larger BMI range.

\begin{tabular}{ll}
\hline KARGER & @ 2008 S. Karger GmbH, Freiburg \\
Fax+497614520714 & $\begin{array}{l}\text { Accessible online at: } \\
\text { www.karger.com/ofa }\end{array}$ \\
$\begin{array}{l}\text { Information@Karger.de } \\
\text { www.karger.com }\end{array}$ &
\end{tabular}




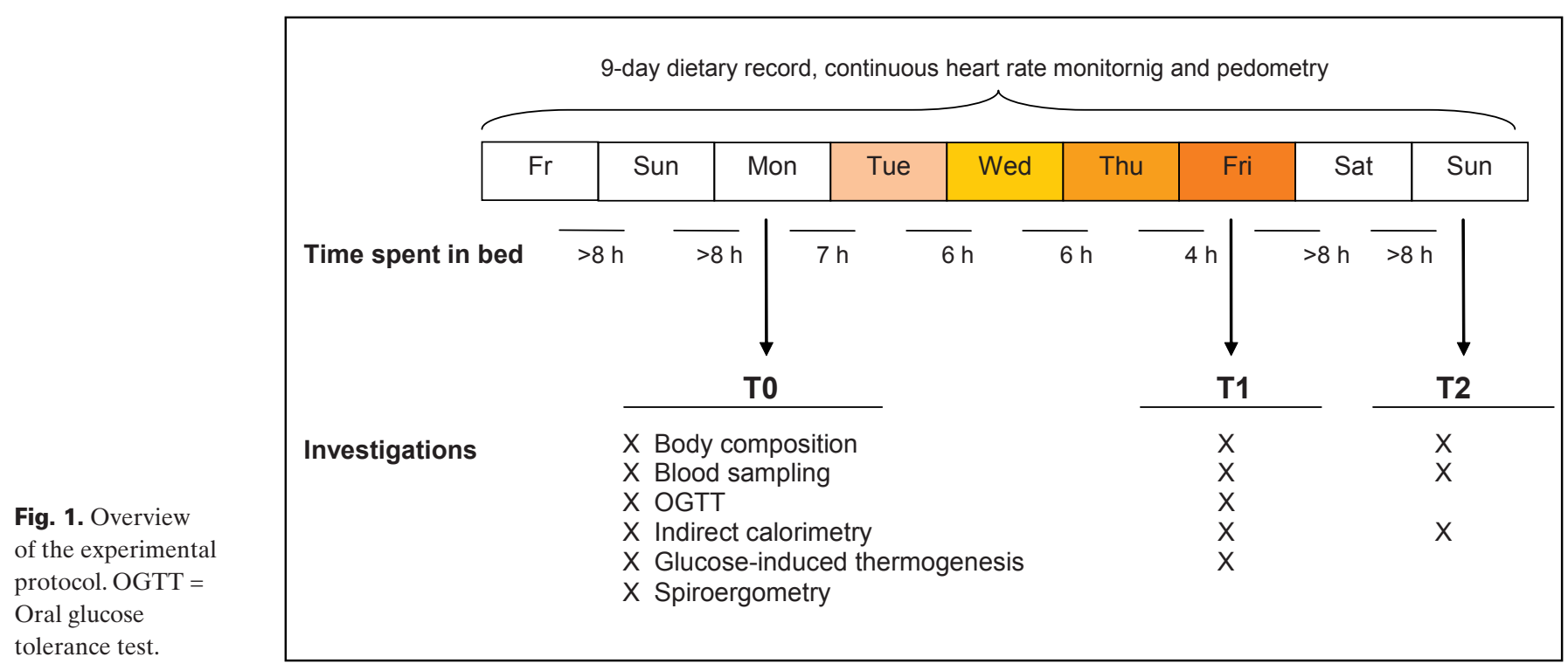

The sleep cycle is closely related to endocrine and metabolic functioning and sympathovagal balance. Sleep restriction leads to an increase in cortisol levels, and a higher sympathetic nervous system (SNS) activity [14]. It may thus augment the energy needed to keep the organism awake, mentally as well as physically. To our knowledge, a possible increase in energy intake as a consequence of impaired anorexigenic and enhanced orexigenic stimuli has not been investigated yet. This may serve as a metabolic adaptation to an increase in energy requirement. Accordingly, total sleep deprivation in rodents led to hyperphagia [15] as well as elevated energy expenditure and ultimately to a reduced body weight [16-18]. In agreement with this observation, patients with insomnia had increased body temperature and heart rate [19] as well as sleeping metabolic rate [20]. Thus, both sides of the energy balance need to be investigated to assess the impact of sleep deprivation on body weight regulation.

The aim of the present study was to investigate the impact of partial sleep deprivation on energy intake as well as all components of energy expenditure (resting energy expenditure (REE), glucose-induced thermogenesis (GIT), physical activity and total energy expenditure (TEE)) and the neuroendocrine regulation of energy balance in young healthy normal weight, overweight and obese women under an ad libitum diet.

\section{Subjects and Methods}

Fourteen 23- to 38-year-old women were recruited by notice-board postings in local supermarkets, university, and sports facilities. All participants were healthy and weight-stable. None had a history of recent illness or endocrinopathy. Subjects were non-pregnant, non-lactating, non-smokers and did not take any medications except oral contraceptives (4 cases). Examinations were performed during the follicular phase of the menstrual cycle. Subjects underwent a basal physical examination including blood pressure and ECG recordings. Habitual sleep duration was reported to lay between 7.5 and $9 \mathrm{~h}$. Non of the participants was shift working, complained about sleep disturbances or traveled across time zones less than 1 month before the study. The study protocol was approved by the local ethical committee of the Christian-Albrechts-University Kiel. Each subject provided informed written consent before participation.

Investigations were performed after 2 nights of $>8 \mathrm{~h}$ sleep/night (T0), after 4 nights of consecutively increasing sleep curtailment ( $7 \mathrm{~h}$ sleep/night, $6 \mathrm{~h}$ sleep/night, $6 \mathrm{~h}$ sleep/night and $4 \mathrm{~h}$ sleep/night; T1) and after 2 nights of sleep recovery ( $>8 \mathrm{~h}$ sleep/night; T2). An outline of the study protocol is given in figure 1. Assessments of body composition, REE, GIT, and blood sampling were carried out in the morning between 7:00 and 11:00 a.m. All subjects slept at home, and compliance was checked by 24-hour heart rate monitoring as described below.

\section{Anthropometric Measurements and Body Composition Analysis}

Body weight was measured to the nearest $0.1 \mathrm{~kg}$ on an electronic scale coupled to the BOD-POD ${ }^{\circledR}$ Body Composition System (Life Measurement Instruments, Concord, CA, USA). Height was measured on a stadiometer to the nearest $0.5 \mathrm{~cm}$. Waist circumference was measured to the nearest $0.5 \mathrm{~cm}$ midway between the lowest rib and the iliac crest while the subject was at minimal respiration. Air displacement plethysmography was performed by the BOD-POD device as described previously [21]. Briefly, subjects were measured in tight fitting underwear and a swimming cap. Two repeated measurements of body volume were performed and averaged. Measured thoracic lung volume was subtracted from body volume. In order to reduce measurement variability caused by repeated lung volume measurements, thoracic lung volume was only measured at T0, and this value was subsequently used for body composition analysis at T1 and T2. BOD-POD software was used to calculate body density as body weight divided by body volume and \% fat mass (\%FM) using Siri's equation (22). Fat free mass (FFM;kg) was calculated accordingly: weight (kg) - fat mass $(\mathrm{kg})$. The coefficient of variation for repeated measurements of $\%$ FM was $2.4 \%$.

\section{Parameters of Energy Intake}

An experienced dietitian provided detailed instructions to the participants about recording of all foods consumed. Dietary records were kept for the whole study period of 10 days. Energy and macronutrient intake was assessed using a software program for data analysis (EBISpro 8.0, WillstättLegelshurst, Germany). Alcohol was not allowed during the study period. All dietary records were tested for plausibility, and records from two subjects were discarded based on Goldberg's cut-off [23]. The period from 
days 1 to 4 was averaged as T0; from days 5 to 8 as T1 and from days 9 to 10 as T2. Coefficients of variantion (CVs) for daily caloric intake were $22.8 \%, 17.4 \%$ and $11.9 \%$ at T0, T1 and T2, respectively. Analogous rating scales (ranging from 1 to 10) were used to collect data on hunger and appetite sensation.

\section{Parameters of Energy Expenditure and Physical Activity}

REE was measured by indirect calorimetry using the ventilated hood system Vmax 29n (SensorMedics ${ }^{\circledR}$; Sensor Medics Deutschland GmbH, Höchberg, Germany) for $30 \mathrm{~min}$ after resting for 5 min during calibration of the system in a metabolic ward at constant humidity $(55 \%)$ and room temperature $\left(22^{\circ} \mathrm{C}\right)$. A mass flow sensor measured volume and airflow. Calibration of flow and gas analyzers was done immediately before each measurement. Flow calibration was performed by a 3-liter calibration syringe, and gas analyzers were calibrated using 2 standard gas concentrations $\left(16 \% \mathrm{O}_{2}, 4 \% \mathrm{CO}_{2} ; 26 \% \mathrm{O}_{2}\right.$, room air $\left.20.94 \%, 0.05 \% \mathrm{CO}_{2}\right)$. During the measurements subjects were awake and lay quietly and motionless. Data were collected every $20 \mathrm{~s}$. $\mathrm{VO}_{2}$ and $\mathrm{VCO}_{2}$ were converted to REE by using the abbreviated Weir equation [24]:

$$
\mathrm{REE}(\mathrm{kcal} / \mathrm{day})=\mathrm{VO}_{2}(3.941)+\mathrm{VCO}_{2}(1.106)
$$

Respiratory quotient (RQ) was calculated from $\mathrm{VCO}_{2} / \mathrm{VO}_{2}$. Data obtained during the first 15 min were omitted. REE was adjusted for differences in FFM (measured by ADP) according to Ravussin and Bogardus [25] by using the following equation:

$$
\begin{aligned}
& \text { REEadj }=\text { REE measured }+((\text { FFM group }(\text { mean })- \\
& \text { FFM measured }) \times \text { slope } *)
\end{aligned}
$$

* The slope is derived from the regression equation between REE and FFM.

The $\mathrm{CV}$ for repeated $\mathrm{REE}$ and $\mathrm{VO}_{2}$ max measurements were 5 and $3 \%$, respectively. A detailed description of the procedure, its accuracy, precision, and stability is reported elsewhere [26]. Subsequent to the measurement of REE, GIT was assessed over $3 \mathrm{~h}$ following an oral glucose tolerance test (OGTT; intake of glucose $1 \mathrm{~g} / \mathrm{kg}$ body weight). During the test the subjects were allowed to listen to an audiobook or to watch documentary DVD. GIT in kJ was calculated from the area under the energy expenditure vs. time curve $(\mathrm{MJ} / \mathrm{day} / 180 \mathrm{~min})$ after subtracting the measure of REE. GIT was also expressed as the mean increase in REE over 180 min as a percentage of the energy intake from glucose consumed (\% energy intake).

TEE was estimated using continuous 24-hour heart rate monitoring (Polar S810; Polar, Kempele, Finland; software Polar ${ }^{\circledR}$ Precision Performance SW 3.0) during the study period. Calculations of TEE are based on intraindividual calibrations of $\mathrm{VO}_{2}$ against heart rate using open circuit indirect calorimetry (Vmax 29n) and ergometry (bicyle ergometer EM 840; Siemens, Basel, Switzerland). TEE is derived from the minute-by-minute recordings of heart rate using the individual regression line for $\mathrm{VO}_{2}$ vs. heart rate. The 'FLEX' method was used as an improvement to discriminate between resting and exercise heart rate. 'FLEX' heart rate is defined as the mean of the highest heart rate under sedentary conditions (e.g. sitting on the bicycle ergometer without pedaling) and the lowest heart rate recorded when performing light work on the ergometer [27].

Individual sleep duration was assessed from 24-hour heart rate monitoring as the period below resting heart rate. Sleeping energy expenditure was derived by multiplication of REE with 0.9 . In four subjects continuous data on heart rate could not be obtained because of a loss in signal transduction from the Polar belt. Data on TEE were omitted in these subjects. To assess the level of physical activity, each subject carried a step counter throughout the study period (exercise plus cool and fresh tissue, Kasper and Richter, Germany), and readings were recorded every day. CVs for TEE and pedometer output were 9.8 and $22.7 \%$, respectively.
Insulin Sensitivity and Hormone Analyses

Blood samples were obtained from an antecubital vein after a minimum 8-hour fasting. Plasma insulin was measured by RIA showing no cross-reactivity with C-peptide and only $14 \%$ with proinsulin (Adaltis, Rome, Italy). Plasma glucose was assayed by using a hexokinase enzymatic method. The homeostasis model assessment [28] was used to calculate insulin resistance by the following formula:

HOMA-IR $=$ fasting insulin $(\mu \mathrm{U} / \mathrm{ml}) \times$ fasting glucose $(\mathrm{mmol} / \mathrm{l}) / 22.5$

As an index of insulin sensitivity, the Matsuda index takes into account both fasting glucose and insulin levels, as well as average glucose and insulin levels during an OGTT [29] and was calculated as follows:

$$
\text { Matsuda index }=\frac{10,000}{\sqrt{\begin{array}{l}
\text { fasting glucose } \times \text { fasting insuling } \times(\text { mean } \\
\text { glucose } \times \text { mean insuling during } \text { OFGTT })
\end{array}}}
$$

OGTT was performed by ingestion of glucose $1 \mathrm{~g} / \mathrm{kg}$ body weight in 300 $\mathrm{ml}$ water. Venous blood samples were taken at $0,15,30,45,60$ and $90 \mathrm{~min}$. Blood samples for determination of leptin and ghrelin were collected into tubes containing EDTA. They were immediately centrifuged at $10{ }^{\circ} \mathrm{C}$ for $20 \mathrm{~min}$ at $3,000 \mathrm{rpm}$, and the plasma stored at $-40^{\circ} \mathrm{C}$. RIA test Kits (LINCO Research, St. Charles, MS, USA) using the double antibody/PEG technique were used for determination of plasma leptin and total ghrelin. Analytical sensititvity, intra- and interassay CVs were $0.5 \mathrm{ng} / \mathrm{ml}, 3-8 \%$ and $4-8 \%$ for leptin and $93 \mathrm{pg} / \mathrm{ml}, 3-10 \%$ and $14-16 \%$ for ghrelin, respectively. All samples of each subject were analyzed in duplicate and in one run. Plasma levels of leptin showed a high correlation with fat mass $(r=0.89$, $\mathrm{p}<0.001$ at $\mathrm{T} 0$ ), and the ratio of plasma leptin divided by fat mass was calculated. Serum concentrations of non-protein-bound triiodothyronine (fT3), thyroxine (fT4) and cortisol were measured by competitive analogous immunoassay and competitive chemiluminescent enzyme immunoassay (Immulite, DPC Diagnostic Products Corporation, Los Angeles, CA, USA).

\section{Statistics}

Descriptive statistics are given as means \pm SD. A p value $<0.05$ was considered statistically significant. Analyses were conducted using SPSS for Windows software (SPSS Inc., Chicago, IL, USA). Comparisons between two time points (e.g. glucose-DIT and results from the OGTT at T0 and T1) were compared by Wilcoxon test. Comparisons between subgroups of lean and overweight women were performed by Mann-Whitney U test. Comparisons between three time points (T0, T1, T2) were performed by repeated measures analysis of variance (MANOVA) using a TurkeyKramer multiple comparison post hoc test (calculation with NCSS trial version, 2006; Kaysville, UT USA). Relationships between variables were examined using Pearson's product-moment correlation coefficients. Areas under the insulin and glucose plasma concentration vs. time curves above the basal levels and AUCs of GIT above REE were calculated by trapezoidal rule.

\section{Results}

\section{Impact of Sleep Loss on Energy Intake and Energy Balance} Basal characteristics of the study population are presented in table 1. Eight subjects were normal weight (BMI 18.5$24 \mathrm{~kg} / \mathrm{m}^{2}$ ), 3 were overweight (BMI $25-29 \mathrm{~kg} / \mathrm{m}^{2}$ ), and another 3 were obese $\left(\mathrm{BMI}>30 \mathrm{~kg} / \mathrm{m}^{2}\right)$. In table 2 , the baseline (T0) values of nutritional status, energy intake, energy expenditure, 
Table 1. Basal characteristics of the study population (14 women)

\begin{tabular}{lll}
\hline & Means \pm SD & Range \\
\hline Age, years & $27.5 \pm 5.3$ & $23-38$ \\
Height, cm & $169.5 \pm 6.7$ & $161-182$ \\
Weight, $\mathrm{kg}$ & $73.5 \pm 14.3$ & $59.8-98.3$ \\
$\mathrm{BMI}, \mathrm{kg} / \mathrm{m}^{2}$ & $25.8 \pm 5.8$ & $20.0-36.6$ \\
Waist circumference, cm & $87.3 \pm 14.7$ & $70.0-115.0$ \\
BPsys, $\mathrm{mm} \mathrm{Hg}$ & $119 \pm 8$ & $110-130$ \\
BPdias, $\mathrm{mm} \mathrm{Hg}$ & $79 \pm 6$ & $70-85$ \\
VO $_{2}$ peak, $1 / \mathrm{min}$ & $2.74 \pm 0.33$ & $2.15-3.18$ \\
\hline
\end{tabular}

BPsys = systolic blood pressure $;$ BPdias = diastolic blood pressure $; \mathrm{VO}_{2}$ peak $=$ peak exercise oxygen uptake during ergometry.

Table 2. Parameters of nutritional status, energy intake, energy expenditure, physical activity and endocrine profile at baseline (T0), during follow up at maximal sleep deprivation (T1) and after sleep recovery (T2)

\begin{tabular}{|c|c|c|c|}
\hline & $\mathrm{T} 0$ & $\mathrm{~T} 1$ & $\mathrm{~T} 2$ \\
\hline Sleep duration, h/night ${ }^{\mathrm{a}}$ & $9.02 \pm 0.96$ & $5.49 \pm 0.59 *$ & $9.35 \pm 0.84^{\dagger}$ \\
\hline Weight, kg & $73.5 \pm 14.3$ & $73.9 \pm 14.3^{*}$ & $73.4 \pm 14.3$ \\
\hline Fat mass, $\%$ & $30.4 \pm 9.2$ & $29.8 \pm 9.2$ & $31.0 \pm 9.4$ \\
\hline $\mathrm{FFM}, \mathrm{kg}$ & $50.2 \pm 6.1$ & $50.9 \pm 5.6$ & $49.6 \pm 5.4$ \\
\hline $\begin{array}{l}\text { Energy intake, MJ/day } \\
\quad(\mathrm{n}=12)^{\mathrm{a}}\end{array}$ & $8.83 \pm 1.07$ & $10.57 \pm 2.12^{*}$ & $9.08 \pm 1.62$ \\
\hline $\begin{array}{l}\text { Carbohydrates, E\% } \\
\qquad(\mathrm{n}=12)^{\mathrm{a}}\end{array}$ & $52.5 \pm 7.5$ & $55.0 \pm 9.2$ & $50.7 \pm 9.0$ \\
\hline Fat, $\mathrm{E} \%(\mathrm{n}=12)^{\mathrm{a}}$ & $34.3 \pm 6.2$ & $31.8 \pm 7.9$ & $35.3 \pm 8.2$ \\
\hline Protein, $E \%(n=12)^{a}$ & $12.8 \pm 1.8$ & $13.0 \pm 3.5$ & $13.3 \pm 2.7$ \\
\hline Appetite, score ${ }^{\mathrm{a}}$ & $5.2(2.9-6.5)$ & $5.3(4.3-7.3)$ & $5.3(3.9-8.1)$ \\
\hline Hunger, score ${ }^{a}$ & $4.5(2.3-6.0)$ & $4.3(1.3-6.3)$ & $4.7(2.9-7.6)$ \\
\hline REE, MJ/day & $6.29 \pm 0.51$ & $6.41 \pm 0.59$ & $6.25 \pm 0.64$ \\
\hline REEadj, MJ/day & $6.32 \pm 0.57$ & $6.37 \pm 0.60$ & $6.33 \pm 0.47$ \\
\hline TEE, MJ/day $(\mathrm{n}=10)$ & $10.21 \pm 2.15$ & $11.43 \pm 3.46$ & $10.41 \pm 3.03$ \\
\hline Physical activity, steps ${ }^{\mathrm{a}}$ & $7,187 \pm 3,896$ & $8,949 \pm 4,371$ & $7,293 \pm 4,468$ \\
\hline Leptin, ng/ml & $17.55 \pm 19.55$ & $21.79 \pm 21.70^{*}$ & $18.75 \pm 17.73$ \\
\hline $\begin{array}{l}\text { Leptin / fat mass, } \mathrm{ng} / \mathrm{ml} \\
\quad \times \mathrm{kg}^{-1}\end{array}$ & $0.63 \pm 0.37$ & $0.81 \pm 0.44 *$ & $0.71 \pm 0.35$ \\
\hline Ghrelin, pg/ml & $801.2 \pm 332.6$ & $798.4 \pm 356.7$ & $875.7 \pm 333.4$ \\
\hline $\mathrm{fT} 3, \mathrm{pg} / \mathrm{ml}$ & $3.05 \pm 0.61$ & $3.64 \pm 0.79 *$ & $3.11 \pm 0.46^{\dagger}$ \\
\hline $\mathrm{fT} 4, \mathrm{ng} / \mathrm{dl}$ & $1.13 \pm 0.13$ & $1.23 \pm 0.12 *$ & $1.15 \pm 0.13^{\dagger}$ \\
\hline Cortisol, $\mu \mathrm{g} / \mathrm{dl}$ & $16.89 \pm 6.48$ & $18.86 \pm 6.91$ & $17.79 \pm 6.79$ \\
\hline
\end{tabular}

*Significantly different from $\mathrm{T} 0 ; \mathrm{p}<0.05$.

$\dagger$ Significantly different from $\mathrm{T} 1, \mathrm{p}<0.05$, MANOVA.

aThe period from days $1-4$ is averaged as T0; from days $5-8$ as T1, and from days $9-10$ as T2.

physical activity, and endocrine profile are compared with follow-up at maximal sleep deprivation (T1) and after sleep recovery (T2). When compared with days 1-4 (T0), mean sleep duration at $\mathrm{T} 1$ significantly decreased by $\sim 3 \mathrm{~h}$ per night, whereas it subsequently increased again by $4 \mathrm{~h}$ at $\mathrm{T} 2$.

Energy intake increased by $+20 \%$ during the period of sleep loss (T1) when compared with day 1-4 (T0). The mean in-
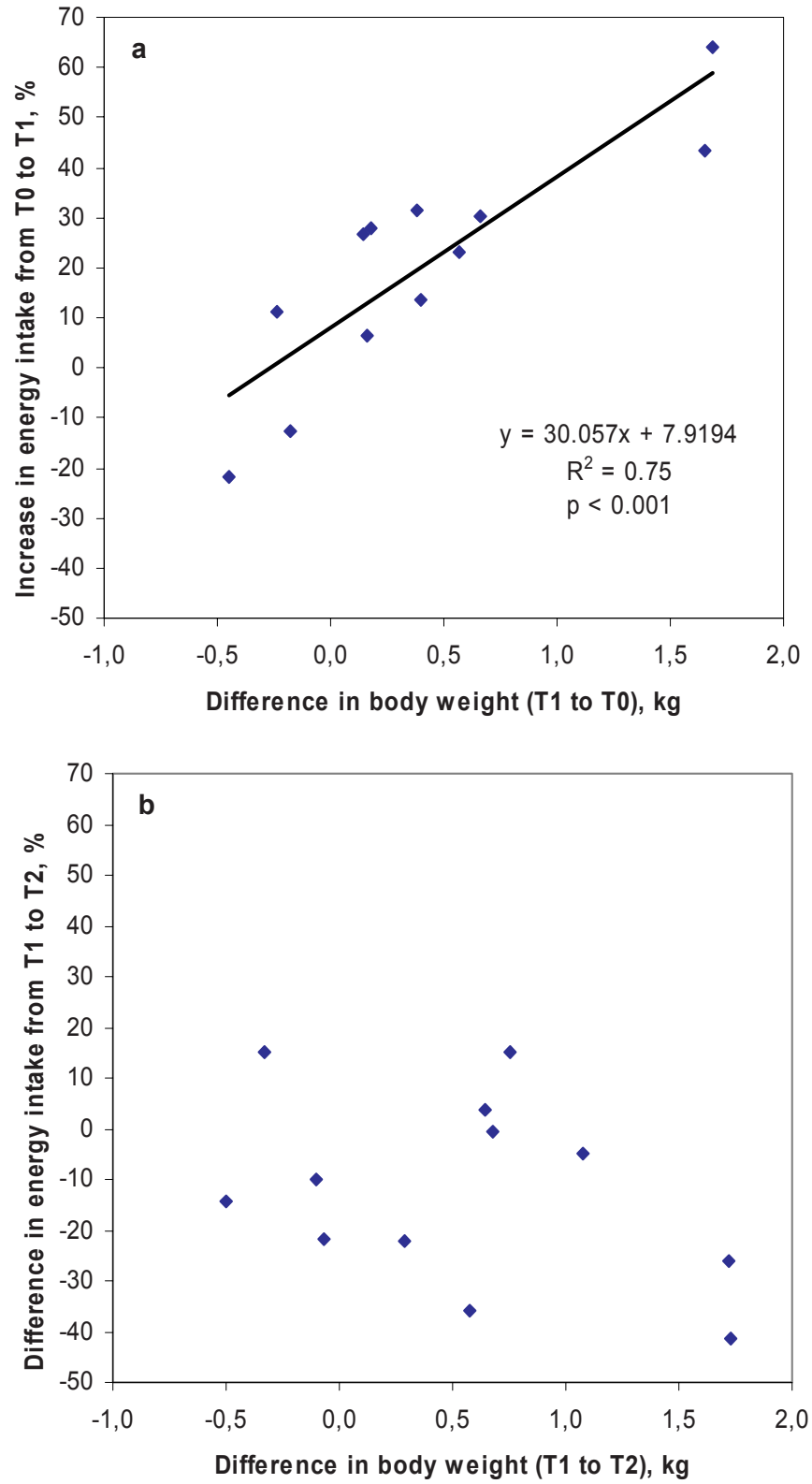

Fig. 2. Relationships between a the sleep restriction induced increase in energy intake and body weight from T0 to T1 and $\mathbf{b}$ the difference in energy intake and body weight during sleep recovery (T1-T2). Normal weight women, $\boldsymbol{\square}$ overweight women, $\boldsymbol{\Delta}$ obese women.

crease was $+415 \pm 471 \mathrm{kcal} /$ day, ranging from $+1,172$ to -461 $\mathrm{kcal} /$ day at unchanged relative macronutrient intake. Concomitantly mean body weight increased from T0 to T1 $(+400$ $\pm 619 \mathrm{~g}$ ranging from +1.7 to $-0.4 \mathrm{~kg}$ ). The increase in body weight correlated with the increase in energy intake $(r=0.82$, $\mathrm{p}<0, .001$ ) (fig. 2a) and the decrease in sleep duration ( $\mathrm{r}=$ 0.69; $\mathrm{p}<0.05)$. Basal plasma leptin $(+24 \%)$ and leptin / fat mass $(+29 \%)$ also increased with sleep loss (table 2). When compared with $\mathrm{T} 0$, leptin levels at $\mathrm{T} 1$ were also higher 45 and 90 min following an OGTT ( $p<0.05$ for both time points) 


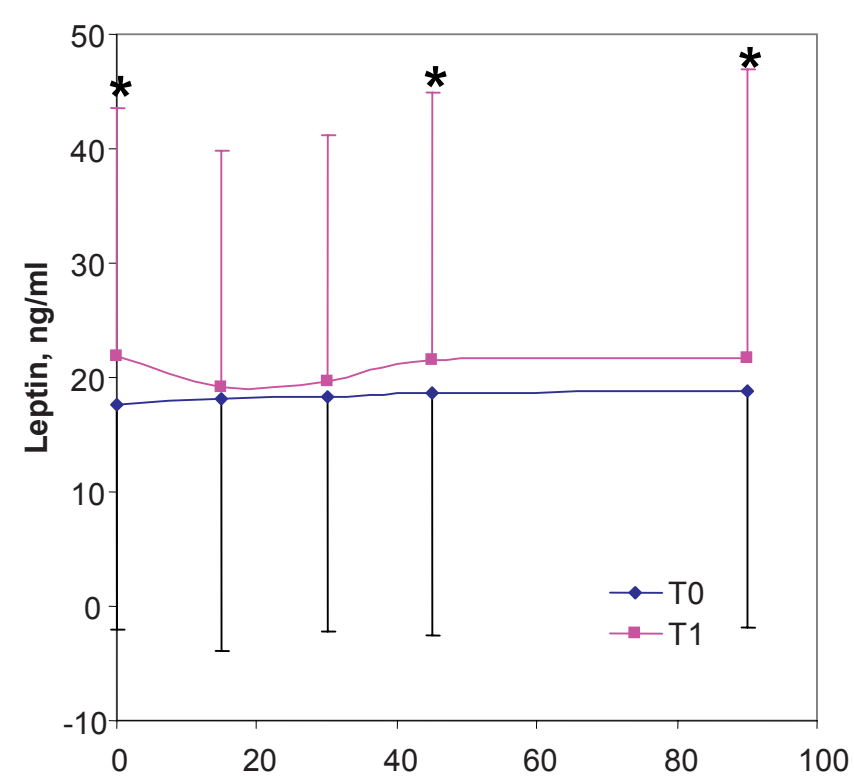

a

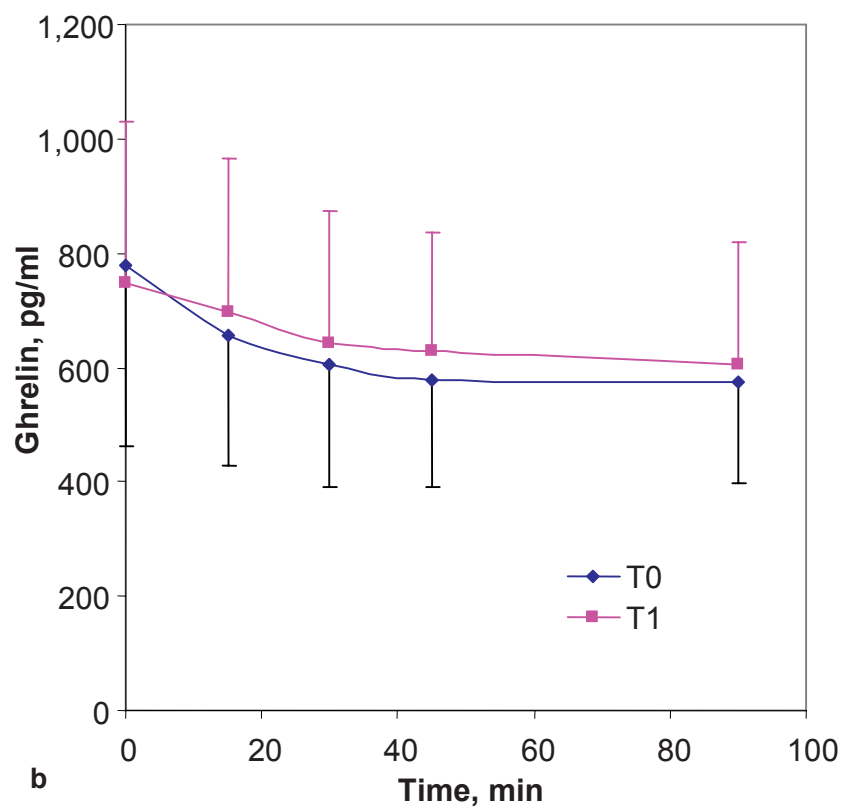

Fig. 3. Basal and post-OGTT a leptin and b ghrelin levels before (T0) and after a period of chronic sleep deprivation (T1). Error bars $=\mathrm{SD}$; * $\mathrm{p}<$ 0.05 .

(fig. 3a). All indicators of a positive energy balance (body weight, energy intake, plasma leptin and leptin / fat mass) returned to baseline levels after sleep recovery at T2. However, there was no significant correlation between the decrease in body weight and the difference in energy intake during sleep recovery ( $\mathrm{T} 1$ to $\mathrm{T} 2$ ) (fig. 2b), but the increase in sleep correlated with a decrease in weight from $\mathrm{T} 1$ to $\mathrm{T} 2(\mathrm{r}=0.67, \mathrm{p}<0.05)$. Mean basal ghrelin levels and ghrelin levels following an oral glucose load (fig. 3b) remained unchanged during intervention. Ratings of hunger and appetite were also unchanged during sleep deprivation and showed no association with energy intake, leptin and ghrelin levels.
Table 3. Results of basal and post load glucose metabolism and GIT to a 3h OGTT

\begin{tabular}{lll}
\hline & T0 & T1 \\
\hline Basal & & \\
$\quad$ Glucose, $\mathrm{mmol} / \mathrm{l}$ & $4.90 \pm 0.36$ & $5.13 \pm 0.62$ \\
Insulin, $\mu \mathrm{U} / \mathrm{ml}$ & $12.52 \pm 7.08$ & $12.15 \pm 6.63$ \\
HOMA-IR & $2.74 \pm 1.65$ & $2.88 \pm 1.54$ \\
Postprandial & & \\
$\quad$ Glucose, $\mathrm{AUC}\left(\mathrm{mg} / \mathrm{dl} \times 180 \mathrm{~min}^{-1}\right)$ & $229.4 \pm 23.9$ & $247.6 \pm 42.4$ \\
Insulin, AUC $\left(\mu \mathrm{U} / \mathrm{ml} \times 180 \mathrm{~min}^{-1}\right)$ & $80.8 \pm 48.5$ & $82.9 \pm 40.5$ \\
$\quad$ Matsuda index & $0.93 \pm 0.39$ & $0.90 \pm 0.42$ \\
GIT, AUC $\left(\mathrm{MJ} / \mathrm{day} \times 180 \mathrm{~min}^{-1}\right)$ & $60.2 \pm 25.8$ & $81.0 \pm 33.5 *$ \\
GIT, $\%$ energy intake & $33.1(7.9-52.2)$ & $47.5(18.6-75.0)^{*}$
\end{tabular}

$* \mathrm{p}<0.01$ for difference between $\mathrm{T} 0$ and $\mathrm{T} 1$ paired samples t-test.

\section{Impact of Sleep Loss on Energy Expenditure Thyroid}

Hormone and Cortisol Levels

There were no significant changes in REE, REEadj, physical activity, TEE, or plasma cortisol levels induced by sleep loss although levels of fT3 and fT4 significantly rose from T0 to T1 (table 2). By contrast, the individual changes in REE after a glucose load significantly increased after sleep loss $(+34 \%)$ (table 3, fig. 4a). There was no relation between REEadj and energy intake at any study phase.

\section{Impact of Sleep Loss on Insulin Sensitivity and Glucose Tolerance}

Sleep deprivation did not affect basal levels of insulin and glucose as well as insulin sensitivity by HOMA-IR (table 3). Mean insulin secretion in response to an oral glucose load and insulin sensitivity assessed by Matsuda index also remained unchanged after sleep loss. However, the change in REE after the period of sleep loss was associated with a concurrent change in Matsuda index $(\mathrm{r}=0.74, \mathrm{p}<0.01)$ and insulin AUC $(\mathrm{r}=-0.58$, $\mathrm{p}<0.05)$. An increase in REE was therefore related to a decrease in insulin sensitivity and a higher insulin secretion.

\section{Impact of Weight Status on the Effects of Sleep Loss}

Weight gain or increases in calorie intake in response to sleep deprivation were not related to initial BMI, \%FM, or waist circumference. By contrast, increases in plasma leptin from T0 to $\mathrm{T} 1$ tended to be related to initial \% FM $(r=0.53, \mathrm{p}=0.051)$. Dividing the study group into 8 women with normal fat mass $<30 \%$ and 6 women with elevated body fat mass $>30 \%$ revealed some difference in hormone levels. In normal fat subjects, ghrelin levels were $904.0 \pm 302.6 \mathrm{pg} / \mathrm{ml}$ at $\mathrm{T} 0,953.3 \pm$ $363.4 \mathrm{pg} / \mathrm{ml}$ at $\mathrm{T} 1$ and $1,032.0 \pm 306.7 \mathrm{pg} / \mathrm{ml}$ at $\mathrm{T} 2$, whereas in women with elevated fat mass plasma ghrelin was significantly lower with $664.2 \pm 346.5,592.0 \pm 237.6$ and $667.3 \pm 257.2 \mathrm{pg} / \mathrm{ml}$ at To, T1 and $\mathrm{T} 2$, respectively ( $\mathrm{p}<0.05$ for all time points). Leptin / fat mass showed a significant difference between 


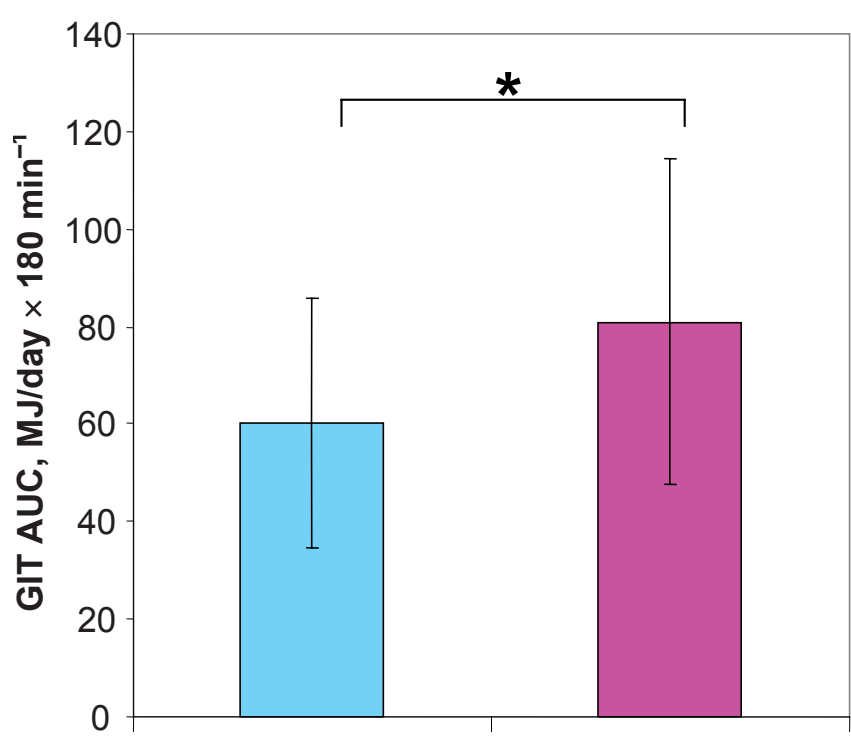

a

TO

T1

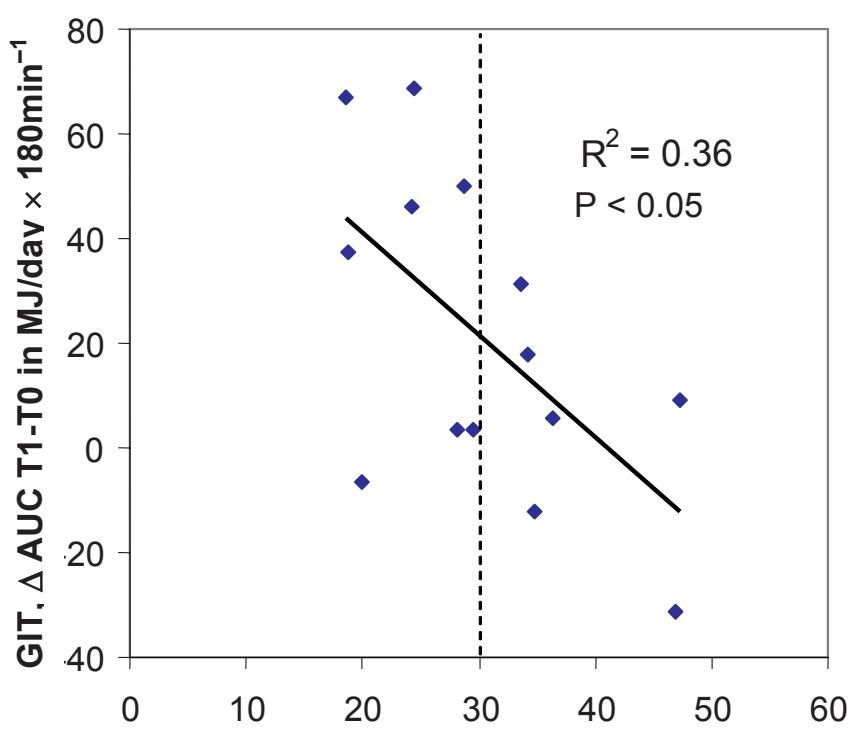

b

Fat mass $\mathrm{ADP}$ T0, \%

Fig. 4. a Sleep loss lead to an increase in GIT that was b dependent on body fat mass. Error bars $=\mathrm{SD}$; fat mass $\mathrm{ADP}$ T0, percentage of fat mass measured by air displacement plethysmography at $\mathrm{T} 0$.

women with normal and elevated fat mass. In normal fat subjects leptin / fat mass was $0.46 \pm 0.16 \mathrm{ng} / \mathrm{ml} \times \mathrm{kg}^{-1}$ at $\mathrm{T} 0,0.65 \pm$ $0.39 \mathrm{ng} / \mathrm{ml} \times \mathrm{kg}^{-1}$ at $\mathrm{T} 1$ and $0.61 \pm 0.35 \mathrm{ng} / \mathrm{ml} \times \mathrm{kg}^{-1}$ at $\mathrm{T} 2$, whereas in women with elevated fat mass leptin / fat mass was higher $\left(0.85 \pm 0.46 \mathrm{ng} / \mathrm{ml} \times \mathrm{kg}^{-1}\right.$ at T0, $1.03 \pm 0.44 \mathrm{ng} / \mathrm{ml} \times \mathrm{kg}^{-1}$ at $\mathrm{T} 1$, and $\left.0.84 \pm 0.34 \mathrm{ng} / \mathrm{ml} \times \mathrm{kg}^{-1}\right)$, with significant group differences at T1 only $(\mathrm{p}<0.05)$. A higher $\% \mathrm{FM}$ at T0 correlated with higher $\mathrm{T} 0$ to $\mathrm{T} 1$ increases in carbohydrate intake $(\mathrm{r}=$ $-0.64 ; \mathrm{p}<0.01)$.

Basal cortisol levels were significantly higher in lean women compared with women with elevated fat mass (20.28 \pm 4.25 vs.
$12.37 \pm 6.41 \mu \mathrm{g} / \mathrm{dl} ; \mathrm{p}<0.05)$. With regard to energy expenditure and stress response, a higher basal \%FM was related to a lower increase in fT3 $(\mathrm{r}=0.56 ; \mathrm{p}<0.05)$ and cortisol levels $(\mathrm{r}=0.70, \mathrm{p}<0.01)$ from T0 to T1. A higher initial waist circumference and a higher \%FM were also related to a lower increase in GIT $(\mathrm{r}=-0.55, \mathrm{p}<0.05$ for waist circumference and $\mathrm{r}=-0.60, \mathrm{p}<0.05$, for $\% \mathrm{FM}$ ), (fig. $4 \mathrm{~b}$ ).

\section{Discussion}

To our knowledge this is the first controlled study that investigates the consequences of partial sleep deprivation on energy balance under an ad libitum diet. After a period of 4 days with consecutive sleep curtailment, a approximately $20 \%$ increase of mean daily energy intake was reported, and a significant weight gain occurred (table 2). Unfortunately, the mean weight gain of $0.4 \mathrm{~kg}$ (table 2) was beyond the precision of body composition analysis by ADP so that the change in FFM and fat mass may not be interpreted.

In young normal weight men, sleep deprivation led to increased ghrelin and lower leptin levels $[11,14]$. Ghrelin, an orexigenic signal from the stomach, increases appetite [13], whereas the adipocytokine leptin confers an anorexigenic, satiating signal to the hypothalamic centers of appetite control $[12,30]$. In the present study the finding of increased plasma leptin and unchanged ghrelin levels after partial sleep deprivation (table 2) might be a consequence of a positive energy balance. Since overfeeding for 3 days was shown to increase leptin levels [31], plasma leptin levels reflect both energy stores (adipose tissue) and recent food intake. Hence we may speculate that the spontaneous compensation of increased appetite led to a higher energy intake under an ad libitum diet, and consequently plasma levels of leptin increased, whereas ghrelin levels remained unchanged.

It is a limitation of our study that the small number in the subgroups of normal weight, overweight and obese women does not allow separate analyses by weight status. However, interindividual susceptibility to sleep loss-induced weight gain varied in our subjects (fig. 2a). Two women even slightly decreased their daily energy intake in response to sleep curtailment. The underlying mechanisms by which sleep debt causes endocrine dysregulation of energy balance remain unknown. Secretion of leptin has been shown to be inhibited by SNS activity [32]. An increase in sympathovagal balance has been reported in healthy subjects after 6 days of partial sleep restriction [13], whereas others did not confirm these findings [33]. An increase in sympathovagal balance may also be caused by a decrease in vagal tone since some studies showed an inhibitory effect of parasympathetic activity on ghrelin production $[13,34,35]$.

Mean morning levels of cortisol tended to increase after sleep loss, but the difference did not reach statistical significance due to a high variance (table 2). There was also no significant 
effect of sleep loss intervention on basal and post OGTT insulin levels in our subjects, suggesting the absence of insulin resistance (table 3). Although mean sleep loss-induced changes in REE and insulin sensitivity were not significant (tables 2,3), a high interindividual variance was observed, and an increase in REE was related to a decrease in insulin sensitivity or a higher insulin secretion. Insulin resistance and hyperinsulinemia may lead to a higher REE by increasing protein turnover, futile cycling, gluconeogenesis and the activity of the sympathetic nervous system [for review see 36]. Insulin resistance may thus be seen as a compensatory mechanism preventing weight gain $[37,38]$.

In contrast to cortisol and insulin, basal levels of fT3 and fT4 significantly increased from $\mathrm{T} 0$ to $\mathrm{T} 1$ which may add to an increase in metabolic rate. However, we found no significant effect of sleep loss on REE, TEE , and physical activity. By contrast, GIT significantly increased ( $+34 \%$, fig. 4 , table 3$)$. The stimulating effect of sleep loss on GIT depended on \%FM (fig. 4) and was higher in women with normal fat mass than in those with elevated fat mass. Accordingly, a higher \%FM was related to a lower increase in fT3 and morning cortisol levels during sleep loss. The lack of any effect of sleep loss on TEE may be due to the imprecision of heart rate monitoring technique. Although at the group level heart rate monitoring provides an estimation of TEE close to that assessed by the doubly labelled water $\left({ }^{2} \mathrm{H}_{2}{ }^{18} \mathrm{O}\right.$, DLW) method, the degree of agreement between the two methods is considerably lower at the individual level $[39,40]$. Therefore, the effect of sleep loss on 24-hour energy expenditure deserves further investigation using more advanced reference methods, e.g. a calorimetric chamber.

Sleep deprivation in healthy young men has been found to result in disturbances of glucose metabolism [14]. In addition, sleep disturbances were found to be a risk factor for the development of diabetes in a retrospective analysis of the Nurses
Health Study [5] and in prospective investigations in middleaged Swedish men [6]. Experimental investigations suggest the activation of neuroendocrine pathways as potential mechanisms by which sleep curtailment may predispose to metabolic disorders. Sleep deprivation was also shown to stimulate the hypothalamo-pituitary adrenal (HPA) axis [41]. Chronic sleep loss may thus mimic the metabolic effects of stress via activation of the SNS and HPA axis. The sympatho-adrenomedullary system is involved in the metabolic response to carbohydrate intake. In young adults, postprandial epinephrine levels follow a biphasic pattern that is inversely related to that of glucose and insulin [42]. Since the effects of sleep loss on carbohydrate metabolism and endocrine function are similar to those observed in normal aging, sleep debt was suggested to increase the severity of age-related chronic disorders [43]. However, our short time sleep curtailment intervention in healthy women had no effect on basal and post OGTT glucose metabolism (table 3). This does not rule out any longtime adverse effect of chronic sleep loss in habitual sleep restriction on insulin sensitivity and glucose metabolism.

In conclusion, we have shown that sleep loss effects energy intake and leads to a net weight gain. Because GIT and thyroid hormone levels (fT3 and fT4) also increased during sleep loss, it can be suggested that energy expenditure might also be influenced by sleep restriction. Therefore, the effect of sleep loss on energy expenditure needs to be specifically addressed in future studies using reference methods for TEE such as a caloric chamber. The stimulating effects of sleep loss on GIT, fT3, and fT4 levels were inversely related to body fat mass suggesting that a higher fat mass inhibits the increase in thermogenesis, thus favoring weight gain.

\section{Acknowledgement}

There are no conflicts of interest.

\section{References}

1 Flegal KM, Carroll MD, Ogden CL, Johnson CL: Prevalence and trends in obesity among US adults, 1999-2000. JAMA 2002;288:1723-1727.

2 Von Kries R, Toschke, AM, Wurmser H, Sauerwald T, Koletzko B: Reduced risk for overweight and obesity in 5- and 6-y-old children by duration of sleep - a cross sectional study. Int J Obes Relat Metab Disord 2002;26:710-716.

3 Sekine M, Yamagami T, Handa K, Saito T, Nanri S, Kawaminami K, Tokui N, Yoshida K, Kagamimori S: A dose-response relationship between short sleeping hours and childhood obesity: results of the Toyama Birth Cohort Study. Child Care Health Dev 2002;28:163-170.

4 Taheri S, Lin L, Austin D, Young T, Mignot E: Short sleep duration is associated with reduced leptin, elevated ghrelin, and increased body mass index (BMI). Sleep 2004;27:A146-147(abstract).
5 Ayas NT, White DP, Al-Delaimy WK, Manson JE, Stampfer MJ, Speizer FE, Patel S, Hu FB: A prospective study of self-reported sleep duration and incident diabetes in women. Diabetes Care 2003;26:380-384.

6 Nielsson PM, Roost M, Engstrom B, Hegblad B, Berglund G: Incidence of diabetes in middle-aged men is related to sleep disturbances. Diabetes Care 2004;27:2464-2469.

7 Gottlieb DJ, Punjabi NM, Newman AB, Resnick HE, Redline S, Baldwin CM, Nieto FJ: Association of sleep time with diabetes mellitus and impaired glucose tolerance. Arch Int Med 2005;165:863-867.

8 Kripke DF, Simons RN, Garfinkel L, Hammond EC: Short and long sleep and sleeping pills. Is increased mortality associated? Arch Gen Psychartry 1979;36:103-116.
9 Johnson EO: Sleep in America: 2000. Results from The National Sleep Foundation's 2000 Omnibus Sleep Poll. Washington, DC, National Sleep Foundation, 2000. www.sleepfoundation.org/atf/cf/\%7 BF6B F2668-A1B4-4FE8-8D1A-A5D39340D9 $C B \% 7 D / 2000 \_p o l l . p d f$.

10 Patel SR, Hu FB: Short sleep duration and weight gain: a systematic review. Obesity (Silver Spring) 2008;16:643-653.

11 Spiegel K, Tasali E, Penev P, VanCauter E: Sleep curtailment in healthy young men is associated with decreased leptin levels, elevated ghrelin levels and increased hunger and appetite. Ann Int Med 2004; 141:846-850.

12 Ahima RS, Saper CB, Flier JS, Elmquist JK: Leptin regulation of neuroendocrine systems. Front Neuroendocrinol 2000;21:263-307. 
13 Van der Lely AJ, Tschop M, Heiman ML, Ghigo E: Biological, physiological, pathophysiological, and pharmacological aspects of ghrelin. Endocr Rev 2004:25:426-457.

14 Spiegel K, Leproult R, Van Cauter E: Impact of sleep dept on metabolic and endocrine function. Lancet 1999;354:1435-1439.

15 Everson CA, Bergmann BM, Rechtschaffen A: Sleep deprivation in the rat: III. Total sleep deprivation. Sleep 1989;12:13-21.

16 Rechtschaffen A, Bergmann BM, Everson CA, Kushida CA, Gilliland MA: Sleep deprivation in the rat: $\mathrm{X}$. Integration and discussion of the findings. 1989. Sleep 2002;25:68-87.

17 Koban M, Swinson KL: Chronic REM-sleep deprivation of rats elevates metabolic rate and increases UCP1 gene expression in brown adipose tissue. Am J Physiol Endocrinol Metab 2005;289:E68-74.

18 Hipolide DC, Suchecki D, Pimentel de Carvalho Pinto A, Chiconelli Faria E, Tufik S, Luz J: Paradoxical sleep deprivation and sleep recovery: effects on the hypothalamic-pituitary-adrenal axis activity, energy balance and body composition of rats. J Neuroendocrinology 2006;18:231-238.

19 Monroe LJ: Psychological and physiological differences between good and poor sleepers. J Abnorm Psychol 1976;72:255-264.

20 Bonnet MH, Arand DL: Insomnia, metabolic rate and sleep restoration. J Intern Med 2003;254:23-31.

21 Bosy-Westphal A, Mast M, Eichhorn C, Becker C Kutzner D, Heller M, Müller MJ: Validation of airdisplacement plethysmography for estimation of body fat mass in healthy elderly subjects. Eur J Nutr 2003;42:207-216.

22 Siri WE: Body composition from fluid spaces and density: analysis of methods; in Brozek J, Henschel A (eds): Techniques for Measuring Body Composition. Washington, DC, National Academy of Sciences, 1961, pp 223-244.

23 Goldberg G, Black A, Jebb S, Cole T, Murgatroyd P, Coward W, Prentice A: Critical evaluation of energy intake data using fundamental principles of energy physiology: 1 . Derivation of cut-off limits to identify underrecording. Eur J Clin Nutr 1991;45: 569-581.
24 Weir JB: New methods for calculating metabolic rate with special reference to protein metabolism. Nutrition 1949;6:213-221.

25 Ravussin E, Bogardus C: Relationship of genetics, age, and physical fitness to daily energy expenditure and fuel utilization. Am J Clin Nutr Suppl 1989;49:968-975.

26 Bader N, Bosy-Westphal A, Dilba B, Müller MJ: Intra- and interindividual variability of resting energy expenditure in healthy male subjects - biological and methodological variability of resting energy expenditure. Br J Nutr 2005;94:843-849.

27 Grund A, Krause H, Kraus M, Siewers M, Rieckert $\mathrm{H}$, Müller MJ: Association between different attributes of physical activity and fat mass in untrained, endurance- and resistance-trained men. J Appl Physiol 2001;84:310-320.

28 Matthews DR, Hosker JP, Rudenski AS, Naylor BA, Treacher DF, Turner RC: Homeostasis model assessment: insulin resistance and beta-cell function from fasting plasma glucose and insulin concentrations in man. Diabetologia 1985;28:412-419.

29 Matsuda M, DeFronzo RA: Insulin sensitivity indices obtained from oral glucose tolerance testing. Comparison with the euglycemic insulin clamp. Diabetes Care 1999;22:1462-1470.

30 Chin-Chance C, Polonsky KS, Schoeller DA: Twenty-four-hour leptin levels respond to cumulative short-term energy imbalance and predict subsequent intake. J Clin Endocrinol Metab 2000;85: 2685-2691.

31 Dirlewanger M, VV, Guenat E, Battilana P, Seematter G, Schneiter P et al: Effects of shortterm carbohydrate or fat overfeeding on energy expenditure and plasma leptin concentrations in healthy female subjects. Int J Obes Relat Metab Disord 2000;24:1413-1418.

32 Rayner DV, Trayhurn P. Regulation of leptin production: sympathetic nervous system interactions. J Mol Med 2001;79:8-20.

33 Irwin M, Thompson J, Miller C, Gillin JC, Ziegler $\mathrm{M}$ : Effects of sleep and sleep deprivation on catecholamine and interleucin-2 levels in humans: clinical implications. J Clin Enocrinol Metab 1999;84: 1979-1985.
34 Sugino T, Yamaura J, Yamagishi M, Kurose Y, Kojima M, Kangawa K, et al: Involvement of cholinergic neurons in the regulation of ghrelin secretory response to feeding in sheep. Biochem Biophys Res Commun 2003;304:308-312.

35 Heath RB, Jones R, Frayn KN, Robertson MD Vagal stimulation exaggerates the inhibitory ghrelin response to oral fat in humans. J Endocrinol 2004;180:273-281.

36 Weyer C, Bogardus C, Pratley RE: Metabolic factors contributing to increased resting metabolic rate and decreased insulin-induced thermogenesis during the development of type 2 diabetes. Diabetes 1999;48:1607-1614.

37 Trembley A: Is the insulin resistance syndrome the price to be paid to achieve body weight stability? Int J Obes 2005;29:1295-1298.

38 Pannacciulli N, Bunt JC, Ortega E, Funahashi T, Salbe AD, Bogardus C, Krakoff J: Lower total fasting plasma adiponectin concentrations are associated with higher metabolic rates. J Clin Endocrinol Metab 2006;91:1600-1603.

39 Maffeis C, Pinelli L, Zaffanello M, Schena F, Iacumin P, Schutz Y: Daily energy expenditure in free-living conditions in obese and non-obese children: comparison of doubly labelled water $(2 \mathrm{H} 2$ (18)O) method and heart-rate monitoring. In J Obes 1995;19:671-677.

40 Livingstone MB, Prentice AM, Coward WA, Ceesay SM, Strain JJ, McKenna PG, Nevin GB Barker ME, Hickey RJ: Simultaneous measurement of free-living energy expenditure by the doubly labeled water method and heart-rate monitoring. Am J Clin Nutr 1990;52:59-65.

41 Vgontzas AN, Mastorakos G, Bixler EO, Kales A Gold PW, Chrousos GP: Sleep deprivation effects on the activity of the hypothalamic-pituitary-adrenal and growth axes: potential clinical implications. Clin Endocrinol 1999;51:205-215.

42 Penev P, Spiegel K, Marcinkowski T, Van Cauter E: Impact of carbohydrate-rich meals on plasma epinephrine levels: dysregulation with aging. J Clin Endocrinol Metab 2005;90:6198-6206.

43 Spiegel K, Knutson K, Leprould R, Tasali E, Van Cauter E: Sleep loss: a novel risk factor for insulin resistance and type 2 diabetes. J Appl Physiol 2005; 99:2008-2019. 